\title{
Palliative Therapy of Refractory Dyspnea with Low Dose Trans- dermal Applied Buprenorphine: An Observational Study
}

\author{
Fabian Rings $^{1^{*}}\left(\mathbb{D}\right.$, Sven Gottschling ${ }^{1}$ and Patric Bialas ${ }^{2}$ \\ ${ }^{1}$ Center for Palliative Care and Pediatric Pain, Saarland University Hospital, Germany \\ ${ }^{2}$ Department of Anesthesiology, Saarland University Hospital, Germany
}

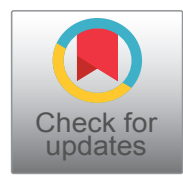

*Corresponding author: Fabian Rings, Center for Palliative Care and Pediatric Pain, Saarland University Hospital, Kirrberger Straße, 66424 Homburg, Germany, Tel: 0049-6841-1628510; 0049-178-451-2988, Fax: 0049-6841-1628519

\begin{abstract}
Objective: Dyspnea is a distressing symptom of many terminal ill patients that has to be treated. Despite recent guideline recommendations there is still great restraint in using opioids for the treatment of dyspnea.

Design: In this report, we investigated, whether transdermal application of buprenorphine (TD BUP) is a safe and efficient way to treat dyspnea. Before applying BUP, dyspnea was scored on numerical analog scales and the patients were examined (assessment of vital parameters, questionnaires). Than treatment with TD BUP $(2.5 \mu \mathrm{g} / \mathrm{h}$ or $5.0 \mu \mathrm{g} / \mathrm{h})$ was started. 48 to 72 hours later the patients were surveyed again. We could survey $\mathrm{N}=21$ patients with refractory breathlessness.

Results: Overall patients were starting with a high average score of 6.24 points on the NAS for base-line dyspnea. This starting score decreased significantly to 3.1 points under TD BUP. Furthermore the intensity of dyspnea attacks was significantly reduced. Vital signs recovered: The breathing rate and pulse rate decreased while $\mathrm{SpO} 2$ increased significantly. We conclude a positive effect on the subjective feeling of dyspnea as well as on its pathophysiology. These results are further supported by the satisfaction of our patients: $85.7 \%$ of them felt (rather) better with our treatment. Most patients would decide again for it.

Conclusions: In summary TD BUP is an effective way to treat base-line dyspnea. Treatment should be started early. It's a promising alternative particularly for out-patients because there have not been any severe complications like breathing depression. Further investigations have to be done to consolidate our results.
\end{abstract}

\section{Keywords}

Dyspnea, Opioids, Buprenorphine, Transdermal application, Palliative, End-of-life care

\section{Background}

Dyspnea is a common and distressing symptom for many terminal ill patients [1]. Not only patients with a primary lung disease (malignant as well as non-malignant) are affected but also patients with several other (malignant) diseases [2-4]. Dyspnea ranges from pediatric patients up to older ones, effecting all age groups $[5,6]$. It has a heavily reducing effect on the quality of life and is often rarely treated or treated too late [7-10]. Although opioid-safety has been described in recent studies [11], there is still great restraint for its use $[12,13]$. The aim of our study is to show a safe and effective way to treat refractory dyspnea, optimally in its early stages. Similar to recent guidelines (which recommend morphine) [14] we chose transdermal applied buprenorphine (TD BUP) as a potent and long-acting opioid. Indeed opioids are first-line therapy and are already used to treat terminal ill patients $[15,16]$, but they are still off-label for the treatment of dyspnea. Until now morphine [1719] and fentanyl [20] are the most common and bestknown substances to treat dyspnea. Every drug and its application route has its advantages and disadvantages. We decided to use TD BUP because of the following reasons: The application of a transdermal drug delivery system (TDDS) once a week is easy, safe [21] and non-invasive $[22,23]$. Further a ceiling-effect for the risk of a breathing depression could be shown for BUP [24], also the pharmacodynamics and-kinetics are advantageous $[25,26]$.

Citation: Rings F, Gottschling S, Bialas P (2020) Palliative Therapy of Refractory Dyspnea with Low Dose Transdermal Applied Buprenorphine: An Observational Study. Int J Anesthetic Anesthesiol 7:110. doi. org/10.23937/2377-4630/1410110

Accepted: July 16, 2020: Published: July 18, 2020

Copyright: (c) 2020 Rings F, et al. This is an open-access article distributed under the terms of the Creative Commons Attribution License, which permits unrestricted use, distribution, and reproduction in any medium, provided the original author and source are credited. 


\section{Methods}

\section{Study design}

From January 2016 to March 2017 we included all adult terminal ill patients with refractory dyspnea at Saarland University Hospital, Homburg, Germany in this observational study. TD BUP has been standard treatment for all patients, there have not been different study groups. The patients had to give their verbal consent with analyzing their data, also they had to be opioid-naive because we used low-dose TD-BUP. Otherwise results would have been distorted/biased. Among a general anamnesis following parameters were assessed:

- Numerical analogue scale from 0 to 10 points for base-line and maximum dyspnea, even though for symptom-burden

- Medical-research-council-breathlessness-scale [27]

- Vital signs: Breathing frequency, pulse frequency and peripheral oxygen saturation $\left(\mathrm{SpO}_{2}\right)$

- Possible side effects like nausea, constipation and fatigue

Afterwards the therapy with low-dose TD BUP (Nor$\operatorname{span}^{\circledR} 2.5 \mu \mathrm{g} / \mathrm{h}$ or $5.0 \mu \mathrm{g} / \mathrm{h}$ ) was started. The dose has been adapted to the severity of basal dyspnea and the body-mass index of our patients. Only if necessary, 100 $\mu \mathrm{g}$ oral fentanyl for treatment of maximum dyspnea-attacks was added (19.2\% of cases). Between 48 and 72 hours later the patients were surveyed again. Among the assessed parameters of the first anamnesis the patients should additionally give their own opinion about the treatment and if they felt relieved. For this we used Likert-scales. This simple way of assessment was appropriate for most of the patients, although they have been compromised by their dyspnea.

\section{Statistical analysis}

Statistical analysis, tables and figures were done using IBM SPSS Statistics ${ }^{\circledR}$ (Version 23.0.0.2). The data measured on numerical analogue scales and the differences for the vital parameters were analyzed with a two-sided t-test between parameters for continuous variables. Also a Spearman's correlation test between initial assessed and follow-up parameters was performed.

\section{Results}

\section{General patient's data}

After $\mathrm{N}=5$ patients had to be excluded from the study (e.g. because of death or palliative sedation), we could include $\mathrm{N}=21$ patients, thereof $53.8 \%$ women.

Table 1: T-test of differences before and under TD BUP.

\begin{tabular}{|c|c|c|c|c|c|c|c|c|}
\hline & \multirow{2}{*}{ Before TD BUP } & \multirow{2}{*}{$\begin{array}{l}\text { Under } \\
\text { TD BUP }\end{array}$} & \multirow{2}{*}{ Mean $\Delta$} & \multirow{2}{*}{ Std. Dev. } & \multirow{2}{*}{$\begin{array}{l}\text { Std. Error } \\
\text { Mean }\end{array}$} & \multicolumn{2}{|l|}{$95 \% \mathrm{Cl}$} & \multirow{2}{*}{$p$-value } \\
\hline & & & & & & Lower & Upper & \\
\hline$\Delta$ Base-line dyspnea (NAS) & 6.24 & 3.10 & -3.143 & 1.652 & 0.360 & -3.895 & -2.391 & 0.000 \\
\hline$\Delta$ Symptom burden (NAS) & 9.24 & 7.76 & -1.476 & 1.601 & 0.349 & -2.205 & -0.748 & 0.000 \\
\hline$\Delta$ Maximum dyspnea (NAS) & 9.19 & 7.52 & -1.667 & 1.880 & 0.410 & -2.522 & -0.811 & 0.001 \\
\hline$\Delta \mathrm{BF}$ (per minute) & 27.29 & 20.10 & -7.190 & 3.124 & 0.682 & -8.613 & -5.768 & 0.000 \\
\hline$\Delta \mathrm{PF}$ (per minute) & 95.86 & 88.43 & -7.429 & 8.863 & 1.934 & -11.463 & -3.394 & 0.001 \\
\hline$\Delta \mathrm{SpO}_{2}(\%)$ & 95.43 & 97.10 & +1.667 & 2.652 & 0.579 & 0.459 & 2.874 & 0.009 \\
\hline
\end{tabular}

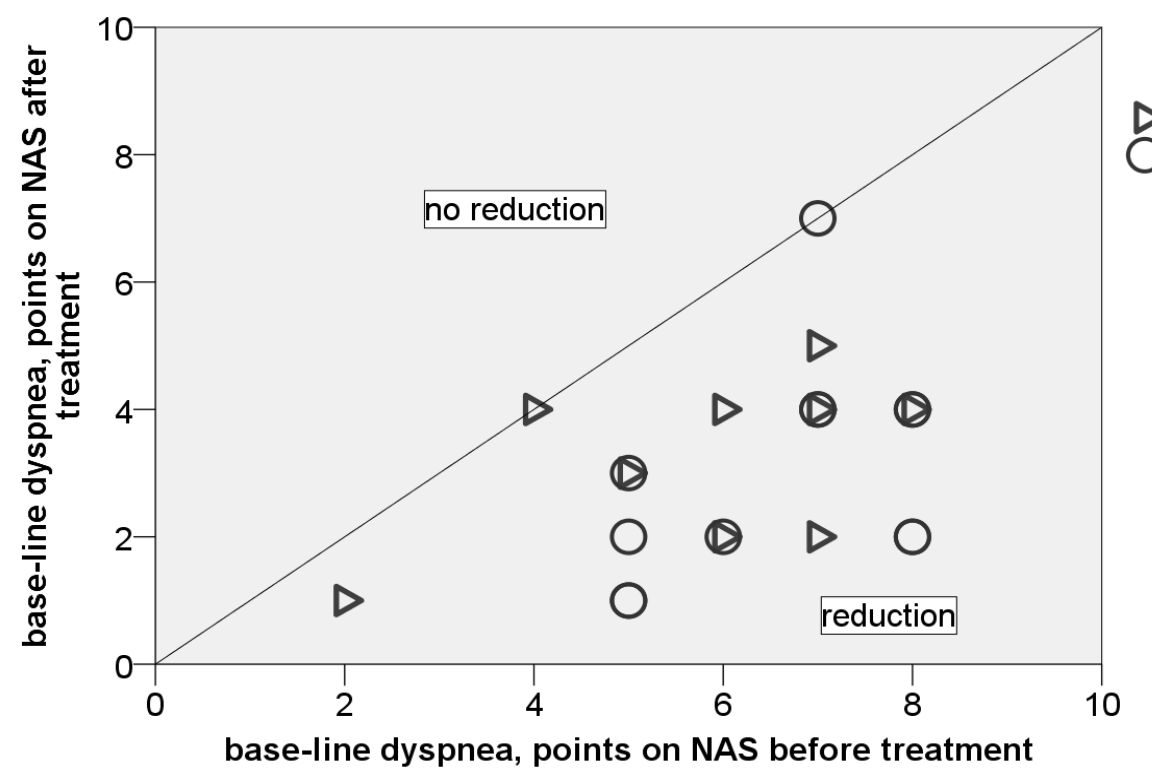

drug

DNorspan 2,5 $\mu \mathrm{g} / \mathrm{h}$ ONorspan $5 \mu \mathrm{g} / \mathrm{h}$

Figure 1: Individual benefit from TD BUP after 48 hours on NAS scale. 
Most patients (92\%) have been cancer patients, $61.9 \%$ had primary lung cancer. The other cancer patients had pulmonary metastases or other reasons for dyspnea like massive ascites. There was no causal therapy available, so that there was no further bias. The mean age was 70.04 years ( $S D \pm 8.9$ years), the mean body mass index $24.93 \mathrm{~kg} / \mathrm{m}^{2}\left(\mathrm{SD} \pm 5.54 \mathrm{~kg} / \mathrm{m}^{2}\right)$ and the mean time between the assessments was $57.8 \mathrm{~h}(\mathrm{SD} \pm 11.6 \mathrm{~h})$. All our patients had severest base-line dyspnea (MRC 4: $11.5 \%$, MRC 5: 88.5\%) and a high symptom burden (Table 1). Taken together we treated mainly elderly, terminal ill cancer patients.

\section{Impact of TD BUP}

Under treatment with TD BUP (Table 1) we detected a decrease of base-line dyspnea to an acceptable level $(-3.10$ points, $(p<0.000)$. Most of the patients $(90.5 \%)$ benefited from treatment (Figure 1). Even the symptom burden $(p<0.000)$ and the severity of dyspnea attacks could be reduced $(p<0.001)$ but not as strong as base line dyspnea. Furthermore we could show an optimized cardiopulmonary status of our patients: The breathing frequency could be downscaled by 7.2 per minute $(p<$ 0.000 ) to roughly 20 per minute, which is nearly physiological. Thereby the pulse frequency decreased $(p<$ 0.001 ) while $\mathrm{SpO}_{2}$ increased $(p<0.009)$. We conclude a positive effect on the subjective feeling of dyspnea as well as on its pathophysiology: Reducing the stress-induced tachycardia and hyperventilation leads to less oxygen consumption. Assessing how our patients themselves thought about this treatment, $85.7 \%$ of them answered to feel (rather) relieved, $81.0 \%$ would decide again for TD BUP. There have not been any severe complications like breathing depression or sedation. $85.7 \%$ of our patients did not have any side effects, $14.3 \%$ had light new upcoming symptoms like nausea or tiredness. These have not been reasonable for canceling our treatment, these patients continued with supportive therapy (like anti-emetics).

\section{Which patient had the most benefit?}

Table 2 shows which parameters correlate with the reduction of base-line dyspnea: As you can see, patients with a high base-line dyspnea before treatment had a significant $(p<0.004)$ better reduction. Furthermore a high initial BF correlated significantly $(p<0.001)$ with a high base-line dyspnea. Accordingly it is important to asses these parameters.

\section{Discussion}

\section{Main findings}

Our investigation shows, that dyspnea despite all medical achievements is still a very distressing symptom of many terminal ill patients. For most patients the symptom burden is very high (physical as well as mental). The therapy often starts to late (no therapy for patients with MRC grade 4 and 5 until getting in contact with the palliative care team). We can confirm the results of Young, et al. [13]. With low-dose TD BUP we could reach a good and effective symptom-control for base-line dyspnea. The doses of $2.5 \mu \mathrm{g} / \mathrm{h}$ and $5 \mu \mathrm{g} / \mathrm{h}$ might have to be raised for opioid-adapted patients or in case of a progressing symptom burden. Starting with low-dose TD BUP offers therapy-escalation. We could measure a positive effect on the cardiopulmonary status of our patients: Breathing frequency and pulse frequency decreased while $\mathrm{SpO}_{2}$ increased. Most of our patients had a benefit and would decide for TD BUP again because they felt better with this therapy. We would like to point out, that in this setting TD BUP was a safe and efficient way of breathlessness treatment $[24,10]$. Restraint against the usage of opioids has not been reasonable. Patients with a high base-line dyspnea and a high breathing frequency as a central pathomechanism profited most; the assessment of these parameters is important. Our results offer another interesting alternative for out-patients in opposite to traditional dyspnea treatment with e.g. subcutaneous or oral morphine [1618]: TD BUP is especially for out-patients easier to apply

Table 2: Spearman's correlation.

\begin{tabular}{|c|c|c|c|c|c|}
\hline & & $\begin{array}{l}\text { Reduction of base- } \\
\text { line dyspnea } \\
\text { (NAS) }\end{array}$ & $\begin{array}{l}\text { Base-line dyspnea } \\
\text { before TD } \\
\text { BUP (NAS) }\end{array}$ & $\begin{array}{c}\text { PF before TD } \\
\text { BUP }\end{array}$ & $\begin{array}{c}\text { BF before TD } \\
\text { BUP }\end{array}$ \\
\hline \multirow{2}{*}{$\begin{array}{l}\text { Reduction of base-line } \\
\text { dyspnea (NAS) }\end{array}$} & $\mathrm{R}$ & 1.000 & $-0.557^{* *}$ & -0.016 & -0.322 \\
\hline & $p$-value & 0 & 0.004 & 0.472 & 0.077 \\
\hline \multirow{2}{*}{$\begin{array}{l}\text { Base-line dyspnea before } \\
\text { TD BUP (NAS) }\end{array}$} & $\mathrm{R}$ & $-0.557^{* *}$ & 1.000 & 0.300 & $0.590^{* *}$ \\
\hline & $p$-value & 0.004 & 0 & 0.068 & 0.001 \\
\hline \multirow{2}{*}{ PF before TD BUP } & $R$ & -0.016 & 0.300 & 1.000 & $0.521^{* *}$ \\
\hline & $p$-value & 0.472 & 0.068 & 0 & 0.003 \\
\hline \multirow{2}{*}{ BF before TD BUP } & $R$ & -0.322 & $0.590^{* *}$ & $0.521^{* *}$ & 1.000 \\
\hline & $p$-value & 0.077 & 0.001 & 0.003 & 0 \\
\hline
\end{tabular}

R: correlation coefficient (1-tailed)

*: p-value $<0.05$

** $p$-value $<0.001$ 
[23] and in our opinion safer to use. Clearly, it should be tested against these other forms of therapy. For the future randomized controlled trials with a higher case number are needed. Patients in an ambulant setting should be treated and surveyed (e.g. by a specialized ambulant palliative care team). However, recruitment is difficult, because many physicians are still restrained against opioids [12]. Additionally an objective assessment and measurement is sometimes difficult due to the compromised and old patients [28].

\section{Limitations}

There is poor control of maximum dyspnea attacks. This is the reason, why the symptom burden did not decrease to an acceptable level. Therefrom a short acting opioid still has to be added $[20,29]$, treatment has still to be improved. A combination seems to be useful. Follow-up time has been short in this observational study and should be increased. It is unclear, how long the effect of relief lasts and when there will be an opioid-dose adaption necessary. Safety and side effects have to be assessed again for higher doses and a higher number of patients. Most patients have been cancer patients. It is not clear, if TD BUP has the same positive effects on non-oncologic patients. That should be further investigated.

\section{Conclusions}

With transdermal applied buprenorphine we could show a promising, safe and efficient alternative to treat dyspnea. In opposite of previous standards application is easier and painless. Our report shows further arguments not to avoid opioids and helps to reduce reservations. The treatment of dyspnea gets improved and patients will benefit from it.

\section{Acknowledgements}

\section{Ethics approval and consent to participate}

All procedures performed in studies involving human participants were done in accordance with the ethical standards of the institutional research committee and with the 1964 Helsinki declaration and its later amendments or comparable ethical standards. Consent to participate could be given orally by the patients, because they have been treated in the same way as not-studypatients. They did not get any different drugs. We performed medical research together with quality measurement of our standards. Therefore our study got formal consent from the local ethics-committee: Ethikkommission des Saarlandes, number: 182/17, 07.09.2017.

\section{Consent for publication}

Not applicable.

\section{Availability of data and materials}

The datasets used and/or analyzed during the current study are available from the corresponding author on reasonable request.

\section{Competing interests}

The authors declare that they have no conflict of interest.

\section{Funding}

This research received no specific grant from any funding agency.

\section{Other acknowledgements}

Preliminary results of this study have been published as a poster-presentation on the EAPC World Congress, Madrid, Spain, $18^{\text {th }}-20^{\text {th }}$ May 2017.

\section{References}

1. Campbell ML (2012) Dyspnea prevalence, trajectories, and measurement in critical care and at life's end. Curr Opin Support Palliat Care 6: 168-171.

2. Martinez Frances ME, Perpina Tordera M, Belloch Fuster A, Martinez Moragon EM, Compte Torrero L (2008) Impact of Baseline and Induced Dyspnea on the Quality of Life of Patients With COPD. Arch Bronconeumol 44: 127-134.

3. Okutan O, Tas D, Demirer E, Kartaloglu Z (2013) Evaluation of quality of life with the chronic obstructive pulmonary disease assessment test in chronic obstructive pulmonary disease and the effect of dyspnea on disease-specific quality of life in these patients. Yonsei Med J 54: 1214-1219.

4. Lim RBL (2016) End-of-life care in patients with advanced lung cancer. Ther Adv Respir Dis 10: 455-467.

5. Meyer S, Reinhard H, Gottschling S, Nunold H, Graf N (2004) Pulmonary dysfunction in pediatric oncology patients. Pediatr Hematol Oncol 21: 175-195.

6. Blinderman CD, Billings JA (2015) Comfort care for patients dying in the hospital. N Engl J Med 373: 2549-2561.

7. Sebastiano Mercadante, Flavio Fusco, Amanda Caruselli, Claudio Cartoni, Francesco Masedu, et al. (2017) Background and episodic breathlessness in advanced cancer patients followed at home. Curr Med Res Opin 33: 155-160.

8. O'Donnell DE, Neder JA, Harle I, Moran-Mendoza O (2016) Chronic breathlessness in patients with idiopathic pulmonary fibrosis: A major challenge for caregivers. Expert Rev Respir Med 10: 1295-1303.

9. Rajala K, Lehto JT, Saarinen M, Sutinen E, Saarto T, et al. (2016) End-of-life care of patients with idiopathic pulmonary fibrosis. BMC Palliat Care 15: 85.

10. Vozoris NT, O'Donnell DE (2016) The need to address increasing opioid use in elderly COPD patients. Expert Rev Respir Med 10: 245-248.

11. Varkey B (2010) Opioids for palliation of refractory dyspnea in chronic obstructive pulmonary disease patients. Curr Opin Pulm Med 16: 150-154.

12. Janssen DJA, Hosson SM de, bij de Vaate E, Mooren KJM, Baas AAF (2015) Attitudes toward opioids for refractory dyspnea in COPD among Dutch chest physicians. Chron Respir Dis 12: 85-92.

13. Young J, Donahue M, Farquhar M, Simpson C, Rocker G (2012) Using opioids to treat dyspnea in advanced COPD: Attitudes and experiences of family physicians and respiratory therapists. Can Fam Physician 58: e401-e407.

14. Deutsche Krebsgesellschaft, Deutsche Krebshilfe, AWMF (2015) Leitlinienprogramm Onkologie: S3-Leitlinie Palliativ- 
medizin: Palliativmedizin für Patienten mit einer nicht heilbaren Krebserkrankung, Langversion 1.1.

15. Bausewein C (2016) Management of refractory breathlessness in patients with advanced disease. Internist (Berl) 57: 978-982.

16. Cabezon-Gutierrez L, Khosravi-Shahi P, Custodio-Cabello S, Muniz-Gonzalez F, Cano-Aguirre MDP, et al. (2016) Opioids for management of episodic breathlessness or dyspnea in patients with advanced disease. Support Care Cancer 24: 4045-4055.

17. Cohen MH, Anderson AJ, Krasnow SH, Spagnolo SV, Citron ML, et al. (1991) Continuous intravenous infusion of morphine for severe dyspnea. South Med J 84: 229-234.

18. Gamborg H, Riis J, Christrup L, Krantz T (2013) Effect of intraoral and subcutaneous morphine on dyspnea at rest in terminal patients with primary lung cancer or lung metastases. J Opioid Manag 9: 269-274.

19. Martins RT, Currow DC, Abernethy AP, Johnson MJ, Toson $B$, et al. (2016) Effects of low-dose morphine on perceived sleep quality in patients with refractory breathlessness: A hypothesis generating study. Respirology 21: 386-391.

20. Hui D, Kilgore K, Park M, Williams J, Liu D, et al. (2016) Impact of prophylactic fentanyl pectin nasal spray on exercise-induced episodic dyspnea in cancer patients: A double-blind, randomized controlled trial. J Pain Symptom Manage 52: 459-468.

21. Coplan PM, Sessler NE, Harikrishnan V, Singh R, Perkel C (2016) Comparison of abuse, suspected suicidal intent, and fatalities related to the 7-day buprenorphine transdermal patch versus other opioid analgesics in the national poison data system. Postgrad Med 129: 55-61.
22. Margetts L, Sawyer R (2007) Transdermal drug delivery: Principles and opioid therapy. Contin Educ Anaesth Crit Care Pain 7: 171-176.

23. Leimüller R (2006) Transdermale Systeme: Wie die Applikation von Opioiden verbessert wird. Deutsches Ärzteblatt 103: 3206.

24. Dahan A, Yassen A, Romberg R, Sarton E, Teppema L, et al. (2006) Buprenorphine induces ceiling in respiratory depression but not in analgesia. Br J Anaesth 96: 627-632.

25. Al-Tawil N, Odar-Cederlof I, Berggren A-C, Johnson HE, Persson J (2013) Pharmacokinetics of transdermal buprenorphine patch in the elderly. Eur $\mathrm{J}$ Clin Pharmacol 69: 143-149.

26. Lüllmann H, Mohr K, Hein L, Martin wehlig (2010) Pharmakologie und Toxikologie. (1 $7^{\text {th }}$ edn) Stuttgart: Georg Thieme Verlag.

27. Stenton C (2008) The MRC breathlessness scale. Occup Med (Lond) 58: 226-227.

28. Mark B Parshall, Richard M Schwartzstein, Lewis Adams, Robert B Banzett, Harold L Manning, et al. (2012) An official American Thoracic Society statement: Update on the mechanisms, assessment, and management of dyspnea. Am J Respir Crit Care Med 185: 435-452.

29. David Hui, Angela Xu, Susan Frisbee-Hume, Gary Chisholm, Margarita Morgado, et al. (2014) Effects of prophylactic subcutaneous fentanyl on exercise-induced breakthrough dyspnea in cancer patients: A preliminary double-blind, randomized, controlled trial. J Pain Symptom Manage 47: 209-217. 